\title{
Employees' Work Patterns-Office Type Fit and the dynamic relationship between Flow and Performance
}

Aida Soriano. Departamento de Psicología Social, IDOCAL, Universitat de València. Valencia (España). Avda. Blasco Ibáñez, 21, 46011, Valencia, España aida.soriano@uv.es

Malgorzata Kozusznik, PhD. Research Group for Work, Organizational and Personnel Psychology (WOPP), Katholieke Universiteit Leuven, Dekenstraat 2, P.O. 3701, 3000 Leuven, Belgium, and Departamento de Psicología Social, IDOCAL, Universitat de València. Valencia, España gosia.kozusznik@kuleuven.be

José M. Peiró, PhD (corresponding author). Departamento de Psicología Social, IDOCAL, Universitat de València, and IVIE. Avda. Blasco Ibáñez, 21, 46011, Valencia, España Jose.M.Peiro@uv.es Telf. 0034963864 489. Fax. 0034963864668

Evangelia Demerouti, PhD. Department of Industrial Engineering \& Innovation Sciences, Human Performance Management, Eindhoven University of Technology. De Zaale, Eindhoven, P.O. Box 513, 5600 MB Eindhoven, The Netherlands e.demerouti@tue.nl

"Declarations of interest: none".

Short title: Work Patterns-Office Type Fit

This article has been accepted for publication and undergone full peer review but has not been through the copyediting, typesetting, pagination and proofreading process, which may lead to differences between this version and the Version of Record. Please cite this article as doi: 10.1111/APPS. 12251

This article is protected by copyright. All rights reserved 
Article type : Original Article

\section{Employees' Work Patterns-Office Type Fit and the dynamic relationship between Flow and Performance}

\section{Abstract}

Organizations must improve their employees' performance in order to compete effectively. Evidence shows that flow experiences enhance performance. However, a dynamic approach to this phenomenon is needed. Furthermore, different work patterns (based on task profiles) can have specific environmental requirements (office types). This research aims to analyze the dynamic relationship between office workers' flow and in-role and extra-role performance, considering work pattern-office type fit as a predictor of the initial level of each of these three variables. Eighty-three workers participated in this diary study. Results of the latent growth model showed a positive association between: 1) the initial levels of flow and in-role and extra-role performance; and 2) the changes in flow and in-role and extra-role performance. Furthermore, Work Pattern-Office Type FIT directly influenced workers' flow. In addition, flow mediated between Work Pattern-Office Type FIT and in-role performance. Our results show that workspaces that fit employees' work patterns are more likely to induce flow, which, in turn, will have beneficial consequences for the organization.

Keywords: misfit; work profiles; workstation; task complexity; white-collar workers; social interaction

This article is protected by copyright. All rights reserved 


\section{Employees' Work Patterns-Office Type Fit and the dynamic relationship between Flow and Performance}

\section{Introduction}

Today's organizations recognize that employees' performance is essential for companies' survival (Campbell \& Wiernik, 2015). Organizations must constantly improve their performance in order to compete effectively (Chang \& Huang, 2005). In this regard, flow is a main construct in the positive psychology movement that has begun to receive considerable research attention (Seligman \& Csikszentmihalyi, 2000). It refers to the holistic feeling of being so engaged in an activity that nothing else seems to matter (Csikszentmihalyi, 1990). In this regard, flow has been identified as a desirable state with positive effects on workers' performance (Demerouti, 2006; see Farina, Rodrigues, \& Hutz, 2018, for a review; Jackson, Thomas, Marsh, \& Smethurst, 2001; Nielsen \& Cleal, 2010). However, although some literature focuses on the flow experience in the work context (Bakker, 2005), research on this topic is still scarce (Demerouti, 2006; Fullagar \& Kelloway, 2009).

First, studies should consider applying research designs that examine changes in flow over time (Mäkikangas, Bakker, Aunola, \& Demerouti, 2010). There is evidence supporting the relationship between flow and performance at work, but the majority of these studies have adopted a cross-sectional approach (Skakon, Nielsen, Borg, \& Guzman, 2010), whereas a dynamic research approach is needed to capture the changing nature of these states (Fullagar $\&$ Kelloway, 2009). Therefore, the application of diary designs can provide better insight into micro processes (Demerouti, Bakker, Sonnentag, \& Fullagar, 2012), such as the dynamic relationship between flow and performance. The present study aims to address these gaps by implementing Latent Growth Modeling (LGM) of diary study data to analyze the dynamic relationship between flow and performance.

Second, limited attention has been paid to how flow develops at work (Nielsen \& Cleal, 2010). Some organizational and job-related characteristics have been linked to flow (Bakker, 2005; Demerouti, 2006; Salanova, Bakker, \& Llorens, 2006) or performance (Baron \& Tang, 2011; Bowling, 2010; Gyekye \& Haybatollahi, 2015; Ibrahim, Al Sejini, \& Al Qassimi, 2004). Nevertheless, knowledge about this phenomenon of flow and its predictors 
and outcomes in the work setting is still limited (Debus, Sonnentag, Deutsch, \& Nussbeck, 2014; Demerouti, 2006; Jackson et al., 2001). Taking into account that flow can be influenced by situational factors (Isham, Gatersleben, \& Jackson, 2019), studies focusing on how flow develops at work could provide useful ideas for designing flow-enhancing environments (Habe, Biasutti, \& Kajtna, 2019).

Several authors have claimed that work should be organized to facilitate flow states (Csikszentmihalyi, 1990), and that organizations should offer environments that match office workers' tasks and requirements, for example, by avoiding unnecessary interruptions, intrusions, or distractions when performing solitary and highly complex work (Rivkin, Diestel, \& Schmidt, 2018). In order to do this, it is important to take into account that, depending on the different tasks workers usually perform in their office work (i.e., work patterns), they may need a specific office type that is more suited to their job than other alternative types (Neufert, 1995). In this regard, studies have shown that if workers perceive their offices to be unsuitable for their work tasks, they tend to report lower wellbeing and performance (Danielsson, 2010; De Clercq, Fontaine, \& Anseel, 2008; Vischer, 2007).

Therefore, the aim of the present research is to study the dynamic relationship between office workers' flow and their in-role and extra-role performance, considering work pattern-office type fit as a predictor of the initial level of these three variables.

\section{Definition of Flow at Work}

Flow has been defined as "a particular kind of experience that is so engrossing and enjoyable [that it is] worth doing for its own sake even though it may have no consequence outside itself" (Csikszentmihalyi, 1999, p.824). It is a state that changes across time and situations, which highlights the dynamic nature of this phenomenon and the need for an adequate approach to capture it (Fullagar \& Kelloway, 2009).

This psychological state has been characterized by an extremely high degree of involvement with and concentration on the task at hand, where one's attention and energy are exquisitely focused on the activity (Fullagar \& Kelloway, 2009). Furthermore, flow may be understood from different perspectives. First, in terms of affectivity, flow could be regarded as a momentary form of eudaimonic wellbeing (Fullagar \& Kelloway, 2009). Second, with regard to cognitive aspects, flow implies that people concentrate fully and are immersed in what they do (Csikszentmihalyi, 1990). And third, from a motivational point of view, feeling flow entails intrinsic motivation that induces people to carry out further activities (Engeser \& Rheinberg, 2008).

This article is protected by copyright. All rights reserved 


\section{Definition of Performance at Work}

Performance is defined as “a function of a person's behavior and the degree to which this behavior helps the organization to obtain its goals" (Ford, Cerasoli, Higgins, \& Decesare, 2011, p.187, see also Motowidlo, Borman, \& Schmit, 1997). It is important to distinguish between the two major facets of performance: in-role performance (i.e., carrying out formal tasks; Williams \& Anderson, 1991) and extra-role performance (i.e., helping others; Moorman, Niehoff, \& Organ, 1993). In our study, we have considered each of these two central facets of performance separately. Thus, our results offer a more complete view of this construct.

\section{Flow and Performance at Work}

Since the beginning of the flow research, a close relationship between flow experiences and performance has been expected (Landhäuber \& Keller, 2012). Theoretically, flow, as an optimal mental state, would be associated with optimal performance (Jackson et al., 2001). This relationship has different explanations. First, from an affective point of view, and considering the happy-productive worker thesis (Cropanzano \& Wright, 1999; Judge, Thoresen, Bono, \& Patton, 2001), flow as a form of eudaimonic wellbeing (Fullagar \& Kelloway, 2009) could promote job performance because workers with high levels of wellbeing usually perform better than those with low levels. Second, from a cognitive point of view, the flow experience is characterized by high levels of concentration and a sense of control, which are facilitators of performance (Eklund, 1996). As such, flow is a highly functional state and should result in better performance by itself (Landhäuber \& Keller, 2012). Furthermore, appropriate activation levels (Jackson et al., 2001), deep concentration, and focused attention (Landhäuber \& Keller, 2012) are important attributes of the flow experience that may transfer to tasks and situations after a flow experience, thus facilitating performance. Third, from a motivational point of view, flow could be seen as a motivating force because workers who experience high levels of flow are motivated to achieve more activities and perform more challenging tasks in order to feel flow again (Engeser \& Rheinberg, 2008).

Along these lines, some empirical evidence supports this relationship between flow and various indicators of in-role (Demerouti, 2006; Kopperud \& Straume, 2009) or extra-role performance (Demerouti, 2006). However, the majority of the studies on wellbeing and its consequences have adopted a cross-sectional approach (Skakon et al., 2010) and only investigated its general tendencies. Flow is predominantly a situational state of mind, rather

This article is protected by copyright. All rights reserved 
than a trait-like characteristic. Thus, it is a dynamic phenomenon that changes across time and situations, and so a dynamic research approach is needed to capture the changing nature of its states (Fullagar \& Kelloway, 2009). Similarly, in the case of performance, the trajectories of employees' performance at work throughout the work day and week also reflect its dynamic nature (Roe, 2014).

Furthermore, research has shown that the variability in a construct at a given time can be quite different from the variability associated with the same construct over time. Hence, it is necessary to articulate the role of time in describing intra-unit change processes (Ployhart $\&$ Vandenberg, 2010). The present study aims to address these gaps by implementing Latent Growth Modeling (LGM) of diary study data to analyze the dynamic intra-personal relationship between flow and performance. LGM allows us to analyze the intra-individual change in a given variable and how this change is related to the intra-individual change in another variable (Gross, Meier, \& Semmer, 2013). It is rarely applied to diary data because diary studies are short-term longitudinal studies that are not suitable for studying long-term growth processes. Therefore, when focusing on the short-term approach, LGM refers more to intra-individual variability (i.e., within approach) than to developmental changes (i.e., interindividual variability or between approaches; Nesselroade, 1991). In other words, analyzing diary data through LGM allows us to answer the question "does the intra-individual change in a variable produce intra-individual changes in another variable?

LGM uses repeated measures to differentiate between the initial level and the change. On the one hand, the initial level or intercept represents the starting point of the regression equation. The intercept factor presents information from the sample about the mean and variance of the collection of intercepts that characterize each individual's growth curve. On the other hand, the change variable refers to the slope of the regression equation and represents the slope of an individual's trajectory (Duncan, Duncan, Strycker, Li, \& Alpert, 2006). Given the cumulative evidence (Demerouti, 2006; Jackson et al., 2001; Kopperud \& Straume, 2009; Landhäuber \& Keller, 2012), the initial level of flow would be expected to have a positive association with the initial performance status. Furthermore, both flow (Fullagar \& Kelloway, 2009) and performance (Roe, 2014) are state variables that change over time and across situations. Therefore, given the affective (Cropanzano \& Wright, 1999; Judge et al., 2001), cognitive (Eklund, 1996; Landhäuber \& Keller, 2012), and motivational factors that link flow and performance (Engeser \& Rheinberg, 2008), and the existence of empirical evidence (Demerouti, 2006; Kopperud \& Straume, 2009), the changes in flow are expected to have a positive association with the changes in performance. Knowledge about This article is protected by copyright. All rights reserved 
this dynamic relationship between flow and performance may be used by supervisors to create flow-inducing conditions in order to maintain high levels of employee performance. These actions are important because a negative change in the daily flow state may have a negative influence on daily performance. Therefore, based on the theoretical arguments and the lack of empirical evidence about the dynamic relationship between flow and performance, the following hypotheses were formulated:

Hypothesis 1: The initial level of flow is positively related to the initial level of in-role (H1a) and extra-role performance (H1b).

Hypothesis 2: The change in flow is positively related to the change in in-role (H2a) and extra-role performance $(\mathrm{H} 2 \mathrm{~b})$.

\section{The Role of the Work Pattern and Office Type Fit (and Misfit)}

Research has shown that some organizational and job-related characteristics can affect organizational outcomes such as flow (Bakker, 2005; Demerouti, 2006; Salanova et al., 2006) or performance (Baron \& Tang, 2011; Bowling, 2010; Gyekye \& Haybatollahi, 2015; Ibrahim et al., 2004). For example, on the one hand, organizational resources (such as social support climate or clear goals) (Salanova et al., 2006) and intrinsic work motivation (Demerouti, 2006) have been linked to work-related flow. On the other hand, the organizational environment (i.e., organizational politics, the stability of the organizational environment, organizational support) (Liu \& Wang, 2016) and job characteristics (such as variety, autonomy) (Johari \& Yahya, 2009) have been related to performance.

In this regard, some literature has also suggested that providing adequate work environments is a main objective of office design (Wohlers, Hartner-Tiefenthaler, \& Hertel, 2017). A wide variety of office types can be classified based on the extent to which employees share their workspaces (e.g., cellular or individual offices, group offices, open plan offices) (Danielsson \& Bodin, 2008). Studies have shown that the office type can influence various work outcomes, such as employees' perceptions of their workplaces, their organizations, and their health and wellbeing (Danielsson, 2010), as well as employees' performance (Jahncke, 2012). This influence may depend on the type of task performed in each kind of office (because each office type is recommended for a specific type of task) (Neufert, 1995).

In this regard, work in offices can include different types of tasks, and these tasks can be characterized by several variables, such as task complexity, task variety, task identity, task significance, and interactions with others at work (Morgeson \& Humphrey, 2006). Literature

This article is protected by copyright. All rights reserved 
has already suggested that task complexity and the degree of interaction with other people at work are the most important work dimensions (Hansen et al., 2014) when the aim is to directly relate job tasks to the space where the work is carried out. In fact, these relations have a significant effect on work outcomes (Wegge, Roth, Neubach, Schmidt, \& Kanfer, 2008).

The activity-based flexible offices specific model (Wohlers \& Hertel, 2017) postulates that organizations should facilitate their employees' need for interaction and concentration because office environments are complex systems that can differ in their architecture and functional features, both of which are relevant to these task characteristics (Bodin, Danielsson, Chungkham, Wulff \& Westerlund, 2014). In this regard, these two task characteristics are core variables related to office workspace: on the one hand, task complexity requires a quiet place to concentrate on cognitively demanding tasks (Davenport, 2013; Hua et al. 2010); on the other hand, interacting with others at work may require privacy, lack of interruptions or interferences, easy listening, etc. (Párraga \& García, 2005). Although other task characteristics may also characterize office work (i.e., variety of the tasks, autonomy), they are not as strongly and directly related to office workspace characteristics.

Additionally, recent empirical studies have shown the influence of the combination of these two core variables on the relationship between different indicators of wellbeing and performance in office workers (Budie, Appel-Meulenbroek, Kemperman \& Wijs-Perree, 2019; Haapakangas, Hongisto, Varjo \& Lahtunen, 2018; Soriano, Kozusznik, \& Peiró, 2018; Soriano, Kozusznik, Peiró, \& Mateo, 2018a). However, further research is needed to investigate the relationships between the patterns of these directly space-related task characteristics and the types of offices that may be more or less suitable for carrying out different types of office jobs.

We understand work patterns to be configurations or profiles of work tasks that are fulfilled and performed through individual and/or collective behaviors (Soriano, Kozusznik, \& Peiró, 2015). Their "theoretically pure" forms would include: 1) Non-interactive, high complexity (e.g., individual tasks that require mental processes, such as data analysis or desk work to plan a marketing campaign); 2) Non-interactive, low complexity (e.g., individual tasks that do not require high cognitive demands, such as data introduction or archiving); 3) Interactive, high complexity (e.g., interactive tasks that require high cognitive demands, such as management tasks and problem solving); and 4) Interactive, low complexity (e.g., interactive tasks that do not require high cognitive demands, such as providing available This article is protected by copyright. All rights reserved 
information to customers, etc.) (Soriano et al., 2015). These different work patterns can have specific organization-related characteristics in terms of environmental requirements such as adequate office types. In this regard, when referring to spatial requirements, Neufert (1995) divides offices into: cellular offices, group offices, and open-plan offices, which, in turn, can be appropriate for different types of work (see Table 1).

Taking into account the possible office type-work pattern match, we can identify two groups: employees who work in an adequate office type for their work pattern (fit group, e.g., workers who usually perform individual and highly complex tasks and work in a cellular office), and employees who work in an inadequate office type for their work pattern (misfit group, e.g., workers who usually perform individual and highly complex tasks and work in an open-plan office).

From a theoretical point of view, the person-organization fit model (Chatman, 1989) suggests that compatibility between workers and organizations is an important element that can enhance our understanding of employee behavior (e.g., performance; De Clercq, Fontaine, \& Anseel, 2008). Moreover, this model highlights that a good fit between the worker and his/her workspace is present when they share similar basic features or when one provides something the other needs (Boon, Den Hartog, Boselie, \& Paauwe, 2011). Therefore, job-person misfit is often understood as an organizational weakness that negatively influences workers' outcomes because a lack of work requirements, as in work design problems, may lead to worse wellbeing- and performance-related processes (Chen, Wu, \& Wei, 2012). Thus, empirical evidence supports a positive relationship between jobperson fit and in-role (Gregory, Albritton, \& Osmonbekov, 2010) and extra-role performance (Goodman \& Svyantek, 1999; Gregory et al., 2010).

Additionally, previous empirical studies have pointed out that companies should provide resources (e.g., adequate office type) that fit the requirements of the workers' tasks (e.g., workers who work alone and have to perform cognitively demanding -complex - tasks, may need quiet workspaces) (Gerdenitsch, Korunka, \& Hertel, 2017; Soriano, Kozusznik, Peiró, \& Mateo, 2018; Vischer, 2007). In this regard, Gerdernitsch and colleagues (2017) suggested that workers who perceive a higher fit between their tasks and their workspace tend to benefit more from the office concept than those who perceive a lower fit (i.e., employees who work in quiet workspaces when they are performing cognitively demanding tasks will be less distracted than employees working in noisy workspaces).

This article is protected by copyright. All rights reserved 
More specifically, workers who perceive that their offices are not suitable for the tasks they have to perform in their work usually report worse job outcomes in terms of their wellbeing and performance processes (Danielsson, 2010; De Clercq et al., 2008; Vischer, 2007). This relationship could be explained by the fact that an adequate office type (for the types of tasks each worker usually performs) may fulfill specific requirements such as privacy, general background interference, personal control over the workstation, or opportunities for cooperation or group identity. Moreover, an office space often conveys not just physical resources, but also functional, symbolic, and social resources. Thus, an office that matches employees' requirements in terms of work patterns may be seen as a set of important resources that enhance employees' motivation (Danielsson, 2010) and lead to a state of optimal functioning (flow) and performance.

A previous study highlighted the moderator role of office type-work pattern fit in the relationship between different indicators of wellbeing and performance (Soriano, Kozusznik, Peiró, \& Mateo, 2018). This effect was significant in all the tested relationships, except in the relationship between flow and performance. One explanation could be that achieving flow implies a previous match between challenges and skills (Csikszentmihalyi \& Lefevre, 1989), which makes the employee less dependent on the environment (the environment might influence the achievement of flow, but once a person reaches this state, s/he may be less influenced by his/her environment). In the present study, we aim to analyze office type-work pattern fit as an antecedent of flow (rather than a moderator) because fit could be a previous necessary condition for achieving this match between challenges and skills (when there is a misfit, the challenges could exceed the skills).

Considering all these ideas, we understand that the fit between the work pattern and an adequate set of resources (a suitable office design and configuration) may be needed to achieve states of flow and performance. Therefore, our main tenet is that this fit, when it occurs, becomes a resource that will significantly increase flow and performance. Thus, we formulate the following hypotheses:

Hypothesis 3: Office type-work pattern fit is positively associated with the in-role (H3a) and extra-role performance level (H3b).

Furthermore, research has highlighted that the flow experience is related to different job characteristics (Demerouti, 2006), such as job (Bakker, 2005) or organizational resources (Salanova et al., 2006). In fact, many factors affect flow, including environmental factors, and so it is important to explore the conditions that are positively related to the ability to

This article is protected by copyright. All rights reserved 
achieve flow (Jackson et al., 2001). There is strong evidence that the flow experience is most likely to be achieved when people perceive a balance between the challenge involved in a situation and their skills in dealing with this challenge (e.g., Bakker, 2005; Csikszentmihalyi, 1990; Ellis, Voelkl, \& Morris, 1994; Fullagar \& Kelloway, 2009). Two of the main conditions that foster flow at work are the balance between challenges and skills and the environmental resources of the work context (Bakker, Oerlemans, Demerouti, Slot, \& Ali, 2011). In this regard, excessively high environmental challenges (e.g., work pattern- office type misfit) may become frustrating (Csikszentmihalyi, 1997; Demerouti, 2006) and make it more difficult to attain a certain level of flow-related psychological skills. Based on these ideas, activation theory (Scott, 1966) proposes that when the activation is too high, workers' performance decreases (Lan, Wargocki, \& Lian, 2011). Thus, we understand that, when an employee is working in a highly demanding environment, the optimal activation level will be exceeded, which, in turn, will negatively affect flow-related psychological skills such as the ability to control one's attention or involvement (Csikszentmihalyi, 1990). In addition, as mentioned above, flow is a state variable that is related to working conditions (Fullagar \& Kelloway, 2009) and, in turn, may influence job performance (Bakker et al., 2011;

Demerouti, 2006). Therefore, we hypothesize the following:

Hypothesis 4: Office type-work pattern fit is positively associated with the level of flow.

Hypothesis 5: Office type-work pattern fit is positively associated with the in-role (H5a) and extra-role performance level (H5b) through the flow level.

Therefore, this research aims to study the dynamic relationship between office workers' flow and their in-role and extra-role performance, considering work pattern-office type fit as a predictor of the development of these three variables. Our study design allows us to analyze dynamic relationships between flow and performance across time. Additionally, the personorganization fit model (Chatman, 1989) suggests that providing an adequate office type for the patterns of tasks an employee usually performs in his/her workspace may promote his/her flow and performance at work. Therefore, our results may be relevant in improving the design of office environments by taking each employee's work patterns into account and, thus, enhancing workers' flow and performance.

\section{Materials and Methods}

\section{Sample and Procedure}

This article is protected by copyright. All rights reserved 
Eighty-three white-collar office workers from five companies in the Valencian Community (Spain) were informed about the study design and the data collection methods. The five organizations cover different sectors. One of them was from higher education (public sector), two were from the furniture industry and banking (private sector), and the last two were professional services (mixed sector). Although the companies were from different sectors, the office work and office needs are transversal across all of them because the offices include similar functions that allow the workers to carry out similar roles (i.e., Bookkeeping, purchase management, or administration and management). Additionally, the offices tend to be similar across the organizations.

Office workers were asked to voluntarily complete the baseline questionnaire (on Monday, one day before the diary data collection week) and fill out short daily questionnaires around the last hour of the workday on four consecutive days (from Tuesday to Friday). We chose a period of a work week (Monday baseline questionnaire, and diary questionnaire from Tuesday to Friday) because studies have shown that workers usually recover over the weekend, and this state is positively related to weekly levels of in-role and extra-role performance (Binnewies, Sonnentag \& Mojza, 2010). Therefore, the weekend allows employees to reverse the negative consequences of job demands and return to the baseline level of functioning (Meijman \& Mulder, 1998). Thus, we analyze a complete cycle of the relationship between flow and performance, avoiding the recovery effect over the weekend. Additionally, following Preacher's (2010) criterion of two growth trajectory factors (intercept and slope $)+1$, at least three repeated measures were needed to test our analyses.

The baseline questionnaire was used to collect all the sociodemographic information, as well as information about employees' work patterns. Regarding the short daily questionnaires, they collected information about employees' levels of flow and in-role and extra-role performance. Because some of the participants were away from the office, we failed to collect data at 49 time points. Therefore, we obtained 283 data collection points. Participants were informed that they could withdraw from the study at any time. Sixty-seven per cent of the sample were women. The participants ranged in age from 20 to 62 years $(M=$ 39.67; SD = 8.84). Eighty-five per cent of the sample had at least a university degree.

These 83 participants were located in 28 different offices. Nine of these offices were cellular offices (1-2 people), and 9 participants (10.84\%) were working in them. Fourteen of these offices were small group offices (3-6 people), and 41 participants (40.40\%) were located in them. Three more offices were group offices (7-19 people), and 15 participants

This article is protected by copyright. All rights reserved 
(18.07\%) were working in them. Finally, the last 2 offices were open offices (more than 20 people), and 18 participants $(21.69 \%)$ were located in them.

The present study was approved by the institutional ethics committee. Additionally, measures were taken to ensure the confidentiality of the data.

\section{Measures}

We used a diary questionnaire and a baseline questionnaire to collect data. Each employee was provided with a tablet containing the questionnaires, and the researchers indicated when they had to fill out the diary. The diary questionnaire assessed state measures that revealed participants' levels of these characteristics on the specific occasions tested. The baseline questionnaire was used to collect sociodemographic data and work pattern information.

State Flow was measured with a two-item scale (White \& Dolan, 2009). The respondents were asked to indicate the extent to which they had had these types of experiences during the past few hours at work (engaged and focused). The response scale ranged from 1 (not at all) to 7 (a lot). The mean Spearman-Brown coefficient for the scale at the four time points was .71.

State Work Performance was measured with six items assessing office workers' performance, three items for in-role performance (sample item: "Now I fulfill all the requirements for my job") and three items for extra-role performance (sample item: "I voluntarily did more than what was required of me") (Williams, 1991; Xanthopoulou, Bakker, Demerouti, \& Schaufeli, 2009a). The respondents were asked to indicate on a scale ranging from 1 (strongly disagree) to 7 (strongly agree) the extent to which they agreed with a series of statements about the work they had been doing during the past couple of hours. The mean Cronbach's $a$ for the in-role and extra-role scales at the four time points were .86 and .74 , respectively.

Finally, Office type-Work Pattern fit (and misfit) was measured using combined information about work patterns and office type. To obtain it, we first measured work patterns using a two-dimensional scale. The first subdimension was composed of one item referring to the frequency of performing complex tasks ("How often does your job require you to do complex tasks?"), and the second subdimension was composed of one item referring to the frequency of interacting with other people at work ("How often does your job require you to work with colleagues, clients, or external people?"). The response scale ranged

This article is protected by copyright. All rights reserved 
from 1 (never) to 4 (quite often). Second, following Neufert's (1995) criteria to classify offices, we determined each employee's office type by considering the number of co-workers in his/her office. In this regard, the size of the group sharing a workspace has also been shown to play a decisive role in more recent taxonomies (Danielsson, 2010). There was "fit" when the work pattern corresponded with the most appropriate office type (see Table 1). There was "misfit" in every other case.

Additionally, we asked employees for some sociodemographic data to control the effect of type of contract, seniority, and educational level on flow. First, temporary workers had lower expectations about job security (De Cuyper \& De Witte, 2007), which has been found to be related to higher organizational commitment and wellbeing (De Witte, 1999, 2005). Second, seniority may be a critical contract characteristic because it is the main way to gain access to privileges and entitlements (De Cuyper \& De Witte, 2007). Third, both seniority (Eisenberger, Jones, Stinglhamber, Shanock, \& Randall, 2005) and educational level (Bennet, Dunne, \& Carré, 2000) might be associated with greater perceived skills.

\section{Data Analysis}

First, because the sample consisted of members of five different organizations, we calculated Box's M to test whether there were relevant differences in the data from the different organizations.

Second, in order to determine each employee's work pattern (considering both task complexity and the interaction with others at work variable), we performed Two-Step Cluster Analysis in SPSS v.22. Because all the variables used in this study were independent and had a normal distribution (skewness $< \pm 2$, and kurtosis $< \pm 7$, Ryu, 2011), we used the loglikelihood approach (SPSS Inc, 2001). In this way, we obtained four groups: 1) Middleinteractive, high complexity (38.55\% of participants), 2) Interactive, high complexity (25.30\% of participants), 3) Interactive, low complexity (27.71\% of participants), and 4) Non-interactive, low complexity ( $8.43 \%$ of participants).

Once we had established these groups, and considering the Neufert (1995) approach (see Table 1), we determined "fit" to be when the work pattern corresponded to its most appropriate office type (37.35\% of participants), and "misfit" to be every other case $(62.65 \%$ of participants).

Third, in order to carry out Latent Growth Modeling to determine the relationships between the variables of interest, we used MPlus software (Muthén \& Muthén, 2015). To this

This article is protected by copyright. All rights reserved 
end, we use a diary approach, which allows us to focus on states that change across time and reflect how an individual feels at certain points in time (Xanthopoulou, Bakker, Demerouti, \& Schaufeli, 2009b). Furthermore, to test the significance of the indirect effects, we produced confidence intervals using the Monte Carlo Method for Assessing Mediation (MCMAM) (Preacher \& Selig, 2012), with 20000 repetitions.

In order to assess the model fit, we examined the RMSEA (Root Mean Square Error of Approximation), CFI (Comparative Fit Index), and TLI (Tucker-Lewis Index) goodness of fit statistics. For the ML method, values of less than .08 for RMSEA typically reflect a reasonable fit, and values greater than .90 for CFI and TLI typically reflect acceptable fit to the data (Little, 2013).

\section{Results}

\section{Preliminary Results: Box M statistic and Classification of Fit and Misfit Groups.}

The results of Box's M statistic ( $\mathrm{p}>.05$ ) showed that the variance-covariance matrix of Flow, In-role performance, and Extra-role performance can be assumed to be equal in the different organizations.

A four-cluster solution was obtained using Two-Step cluster analysis. The results indicated this preferred solution because it minimized the BIC values (101.860) and the change in them between adjacent numbers of clusters selection criteria (-3.222). The average silhouette was .60, and both (task complexity and interaction with others) predictors explained at least $78 \%$ of the cluster analysis results. The final clusters were: 1) "Noninteractive, low complexity"; 2) "Middle Interactive, high complexity; 3) "High interactive, low complexity"; and 4) "High interactive, high complexity". On the basis of this result, and also considering the recommended office type for the type of work performed (Gottschalk, 1994; Laing, Duffy, Jaunzens, \& Willis, 2004; Neufert, 1995), we divided our sample into two groups: a) the "fit" group (workers in an adequate office type for their work pattern); and b) the "misfit" group (workers in an inadequate office type for their work pattern) (see Table $1)$.

Please, insert Table 1 about here

\section{Hypothesis Testing: Latent Growth Modeling.}


Descriptive analyses are shown in Table 2 . We carried out t-tests and $\chi^{2}$ significance tests for the differences in the demographic variables between the groups ("fit" and "misfit"). No differences were found between groups.

Please, insert Table 2 about here

Table 3 presents the means, standard deviations, and significance tests for the differences between the 'fit' and 'misfit' groups in the levels of the variables of interest in our sample. Workers from the FIT and MISFIT groups present similar and average levels of flow and in-role and extra-role performance at the different time points. Table 4 presents the correlations between the interest variables.

Please, insert Table 3 about here

Please, insert Table 4 about here

\section{Latent Growth Model for Flow}

The fit of the linear LGM for flow was good (see Table 5). The results showed that the variance in the level of flow was significant, but the variance in the change in flow was not significant, suggesting that individuals differed from each other in their levels of flow, but not in the rate of mean-level change. The results also showed that the initial level of flow was not associated with its subsequent linear change $(p>.05)$.

Please, insert Table 5 about here

\section{Latent Growth Model for In-role and Extra-role Performance}

The fit statistics for the initial LGM for in-role and extra-role performance were $X^{2}(5)$ $=5.838, p=.32, \mathrm{CFI}=1.00, \mathrm{TLI}=0.99$, and RMSEA $=0.05 ;$ and $X^{2}(5)=10.727, p=.06$, $\mathrm{CFI}=0.97, \mathrm{TLI}=0.96$, and RMSEA $=0.12$, respectively. The modification indices suggested that estimating the covariance between time-specific residuals at T2 and T3 would improve the model fit. After this specification, the fit of the models was good (see Table 5).

This article is protected by copyright. All rights reserved 
First, in the case of in-role performance, the results indicated that there were no mean-level changes in in-role performance over time (see Table 5). The variance in the mean was significant, but the variance in the change factors was not significant. The results also showed that the latent level factor of in-role performance was not associated with its latent linear change factor $(p>.05)$, which means that the relationship between the in-role performance intercept or the starting point and the change in this variable (the initial level will not influence the change intensity in any direction) was not significant. Second, regarding extrarole performance, the results indicated that there were no mean-level changes in extra-role performance over time (see Table 5). However, the variance in the mean and change factors was significant, suggesting that individuals differed from each other, not only in the level of flow, but also in the rate of mean-level change. The results also showed that the latent level factor of extra-role performance was not associated with its latent linear change factor $(p>$ $.05)$.

\section{Association between Flow and In-role and Extra-role Performance}

In order to investigate the relationship between flow and in-role and extra-role performance, the previous LGMs were combined. Figure 1 presents the results of the Latent Growth Modeling. The fit of the associative LGM was $X^{2}(103)=159.134, p=.01, \mathrm{CFI}=$ $0.90, \mathrm{TLI}=0.89$, and RMSEA $=0.08$. The modification indices suggested estimating the covariance between the outcomes at their time-specific residuals. After this specification, the fit of the model was good $X^{2}(99)=137.176, p=.01, \mathrm{CFI}=0.93, \mathrm{TLI}=0.92$, and RMSEA $=$ 0.07. The results showed, first, that the latent initial level factor of flow was positively associated with the latent initial level of both in-role and extra-role performance $(E s t .=0.89$, $p=.01$ and Est. $=0.57, p=.01$, respectively). The higher the level of flow, the higher the level of in-role and extra-role performance. Second, the latent linear change factors of flow and in-role and extra-role performance were also positively associated $($ Est. $=0.55, p=0.01$ and Est. $=1.02, p=.01$, respectively): the greater the change in flow, the greater the change in in-role and extra-role performance. Taken together, these findings offer support for Hypotheses 1a, 1b, 2a and 2b: both the levels and changes in flow and in-role and extra-role performance are positively associated.

The role of Work Pattern-Office Type Fit

This article is protected by copyright. All rights reserved 
The direct effect of Work Pattern-Office Type FIT on workers' flow was significant, thus providing support for Hypothesis $4(E s t .=0.40, p<.05)$. The direct effect of Work Pattern-Office Type FIT on workers' in-role and extra-role performance was not significant, and so the results do not provide support for Hypotheses $3 \mathrm{a}$ and $3 \mathrm{~b}(p>.05)$. When considering the indirect effect through flow, the results support hypothesis 5a regarding the effect on in-role performance $(I C[L L=.01 ; U L=.73])$, but not hypothesis 5 b regarding the effect on extra-role performance $(I C[L L=-.01 ; U L=.58])$.

\section{Please, insert Figure 1 about here}

Finally, Table 6 shows a summary of the hypotheses, highlighting which ones were supported.

Please, insert Table 6 about here

\section{Discussion}

The aim of the present research was to study the dynamic relationship between office workers' flow and their in-role and extra-role performance, considering work pattern-office type fit as a predictor of the development of these three variables. The results show that the initial level of flow is related to the initial level of both in-role and extra-role performance, which means that higher levels of flow are related to higher levels of both types of performance. Additionally, the change in flow produces changes in both in-role and extrarole performance (the greater the increase/decrease in flow during the week, the greater the increase/decrease in in-role and extra-role performance). Furthermore, Work Pattern and Office Type Fit increases the levels of flow and, indirectly, the levels of in-role performance.

\section{Theoretical contributions}

Our expectation about the positive and dynamic association between flow and in-role and extra-role performance received support. The levels of flow and in-role and extra-role performance were strongly related, as were their associated changes over time, providing evidence for a dynamic relationship, as proposed by Demerouti and colleagues (2012). In this regard, these findings are consistent with previous results found between flow and

This article is protected by copyright. All rights reserved 
performance using a cross-sectional approach (Demerouti, 2006), but adding value because the dynamic association received support from our results. Because the variability associated with a construct at a given time can be quite different from the variability associated with a construct over time, it is necessary to articulate the role of time and describe the intra-unit change process (Ployhart \& Vandenberg, 2010) through the use of latent growth modeling, thus yielding a dynamic relationship.

Consistent with our hypothesis, the results also showed that Work Pattern and Office Type Fit was an important covariate that was positively associated with the levels of flow: when there is Fit, the level of flow at work is higher than when there is misfit. Furthermore, in contrast to our hypotheses, Work Pattern and Office Type Fit did not directly affect in-role (Gregory et al., 2010) and extra-role performance (Goodman \& Svyantek, 1999; Gregory et al., 2010). However, Work Pattern and Office Type Fit indirectly influenced in-role performance (through flow). These findings are coherent with results of previous studies indicating that job-person fit may positively influence workers' wellbeing-related processes (Chen et al., 2012), and that flow is related to working conditions (Fullagar \& Kelloway, 2009) and, in turn, may influence job performance (Bakker et al., 2011; Demerouti, 2006). Therefore, the results agree with the person-organization fit model (Chatman, 1989; De Clercq et al., 2008) because they show that compatibility between individuals (i.e., work patterns) and organizations (i.e., office type) affects employees (e.g., flow). Moreover, our results match those from other empirical studies suggesting that person-organization fit affects work outcomes (Goodman \& Svyantek, 1999; O’Reilly III, Chatman, \& Caldwell, 1991). Finally, contrary to what we expected, Work pattern and Office Type Fit did not affect extra-role performance through flow, perhaps because extra-role activities are more related to personal and social variables (Motowidlo \& Van Scotter, 1994) than to environmental characteristics.

\section{Limitations and Strengths}

Some limitations should be taken into account before generalizing the results of the present study. First, we used self-report data. Second, although our results do not allow us to assume causality based on the empirical evidence obtained, these relationships and the mediation of flow have been hypothesized based on theoretical models. In our study, we focus on the effect of the office type-work pattern (mis)fit on flow and performance at work. In order to elaborate the work patterns, we considered the two key variables related to workspace. First, task complexity is related to the environment because it usually requires an

This article is protected by copyright. All rights reserved 
employee to work in a place where he or she can concentrate (because complex tasks involve a high cognitive demand) (Liu \& Li, 2012). Second, interacting with other people at work may require privacy, lack of interruptions or interference, easy listening, etc. (Párraga \& García, 2005). Thus, we have obtained a set of clear and manageable profiles. Future research could identify more complex and numerous patterns that include other variables related to task design (such as the variety of tasks undertaken or the opportunity to have control over the environment where they perform their tasks). Third, the participants in our study had assigned offices; thus, we measured the general self-reported work patterns once. Although the design we chose does not make it possible to capture the moment-to-moment changes in the fit between tasks and environment, the results of our study provide a solid basis for further research. Future research should focus on a population of office workers who use different office spaces and consider the effect of the degree of (mis)fit (rather than differentiating these groups using a dichotomous categorization). These studies may provide insights that facilitate broader flexibility in the allocation of types of offices for different types of work and analyze the relationship between the degree of office type-work fit and its outcomes. Finally, the present study relied on the most widely adopted typology of offices, which includes cellular offices (individual or small groups), group offices, and open offices, without considering emerging types of workspaces (e.g., flexible or combi offices). These office types should be considered in future research.

Despite these limitations, the major strengths of this study include the novel statistical methods employed and the use of diary data, which is still relatively rare in occupational studies. This study used LGM to more thoroughly analyze the relationship between flow and in-role and extra-role performance. The LGM analysis gave us information about the dynamic relationship between these variables. Furthermore, this study highlights the important role of work pattern-office type fit in creating optimal conditions that enhance workers' level of flow.

These findings have important theoretical implications. First, we understand that flow and in-role and extra-role performance vary over time, and our study design allows us to study these changes and their dynamic relationship at different points in time. Second, in addition to merely studying the importance of access to certain types of offices, we contribute to the existing knowledge about the association between different office types and task requirements. Third, our study is one of the first to provide empirical evidence for beneficial effects of office type-work pattern fit on workers' levels of flow and, in turn, on their in-role This article is protected by copyright. All rights reserved 
performance. Therefore, we showed that the office type - work pattern fit conceptualization of person-environment fit theory could describe why activity-based offices are beneficial, thus adding another application of person-environment fit theory to the literature.

\section{Practical Implications and Conclusion}

Additionally, this study also has practical implications. Our results are relevant for improving the design of office environments by taking each employee's work patterns into account and, thus, creating flow-inducing working conditions through workspace (re)design. To enable and sustain beneficial effects such as higher flow levels (and, thus, higher in-role performance), an office type -work pattern fit created by developing activity-based offices is fundamental. Management and human resources departments need to dedicate effort to office environment rearrangement, and workers' participation in decisions about workspaces may help to design an office that truly meets workers' needs.

Flow is an important positive psychological variable that can be influenced by the design of the work and the workspace. Providing adequate workspaces for employees' work patterns is more likely to induce flow, which is likely to have beneficial consequences for the organization. Furthermore, both flow and performance are state variables that are connected to each other in a dynamic relationship. In this regard, our results suggest that flow is a positive psychological state that fully mediates the relationship between certain job characteristics, such as work pattern-office type fit, and state in-role performance of office workers.

It is necessary to explore how different work characteristics can help to create more positive workplaces (Turner, Barling, \& Zacharatos, 2002). Consistent with this idea, this study highlights the importance of promoting flow in workers by creating flow-inducing working conditions through workspace (re)design. As previously suggested (Bakker \& van Woerkom, 2017), organizations should offer resourceful environments that are more conducive to flow, indirectly promoting job performance and increasing the benefits for both the employees and the organization.

\section{REFERENCES}

Bakker, A. B. (2005). Flow among music teachers and their students: The crossover of peak experiences. Journal of Vocational Behavior, 66(1), 26-44. https://doi.org/10.1016/j.jvb.2003.11.001

Bakker, A. B., Oerlemans, W., Demerouti, E., Slot, B. B., \& Ali, D. K. (2011). Flow and performance: A study among talented Dutch soccer players. Psychology of Sport and

This article is protected by copyright. All rights reserved 
Exercise, 12(4), 442-450. https://doi.org/10.1016/j.psychsport.2011.02.003

Bakker, A. B., \& van Woerkom, M. (2017). Flow at Work: a Self-Determination Perspective. Occupational Health Science. https://doi.org/10.1007/s41542-017-0003-3

Baron, R. A., \& Tang, J. (2011). The role of entrepreneurs in firm-level innovation: Joint effects of positive affect, creativity, and environmental dynamism. Journal of Business Venturing, 26(1), 49-60. https://doi.org/10.1016/j.jbusvent.2009.06.002

Bennet, N., Dunne, E., \& Carré, R. (2000). Skills Development in Higher Education and Employment. Buckingham, England: SRHE and the Open University Press.

Boon, C., Den Hartog, D. N., Boselie, P., \& Paauwe, J. (2011). The relationship between perceptions of HR practices and employee outcomes: Examining the role of personorganisation and person-job fit. The International Journal of Human Resource Management, 22(1), 138-162. https://doi.org/10.1080/09585192.2011.538978

Bowling, N. A. (2010). Effects of job satisfaction and conscientiousness on extra-role behaviors. Journal of Business and Psychology, 25(1), 119-130. https://doi.org/10.1007/s10869-009-9134-0

Campbell, J. P., \& Wiernik, B. M. (2015). The Modeling and Assessment of Work Performance. Annual Review of Organizational Psychology and Organizational Behavior, 2, 47-74. https://doi.org/10.1146/annurev-orgpsych-032414-111427

Chang, W. A., \& Huang, T. C. (2005). Relationship between strategic human resource management and firm performance A contingency perspective. International Journal of Manpower, 26(5), 434-449. https://doi.org/10.1108/01437720510615125

Chatman, J. A. (1989). Improving Interactional Organizational Research: A Model of PersonOrganization Fit. Academy of Management Review, 14(3), 333-349. https://doi.org/10.5465/AMR.1989.4279063

Chen, H., Wu, P., \& Wei, W. (2012). New Perspective on Job Burnout: Exploring the Root Cause Beyond General Antecedents Analysis. Psychological Reports, 110(3), 801-819. https://doi.org/10.2466/01.09.13.PR0.110.3.801-819

Cropanzano, R., \& Wright, T. A. (1999). A 5-year study of change in the relationship between well-being and job performance. Consulting Psychology Journal: Practice and Research, 51(4), 252-265. https://doi.org/10.1037//1061-4087.51.4.252

Csikszentmihalyi, M. (1990). Flow: The psychology of optimal experience. New York: Harper Perennial.

Csikszentmihalyi, M. (1997). Finding flow: The psychology of engagement with everyday life. New York: HarperCollins.

This article is protected by copyright. All rights reserved 
Csikszentmihalyi, M. (1999). Implications of a Systems Perspective for the Study of Creativity. In R. J. Sternberg (Ed.), Handbook of Creativity (pp. 313-335). New York, NY: Cambridge University Press.

De Clercq, S., Fontaine, J. R. J., \& Anseel, F. (2008). In search of a comprehensive value model for assessing supplementary person-organization fit. The Journal of Psychology Interdisciplinary and Applied, 142(3), 277-302. https://doi.org/10.3200/JRLP.142.3.277-302

De Cuyper, N., \& De Witte, H. (2007). Job insecurity in temporary versus permanent workers: Associations with attitudes, well-being, and behaviour. Work and Stress, 21(1), 65-84. https://doi.org/10.1080/02678370701229050

De Witte, H. (1999). Job Insecurity and Psychological Well-being: Review of the Literature and Exploration of Some Unresolved Issues. European Journal of Work and Organizational Psychology, 8(2), 155-177. https://doi.org/10.1080/135943299398302

De Witte, H. (2005). Job insecurity: Review of the international literature on definitions, prevalence, antecedents and consequences. SA Journal of Industrial Psychology, 31(4), 1-6. https://doi.org/10.4102/sajip.v31i4.200

Debus, M. E., Sonnentag, S., Deutsch, W., \& Nussbeck, F. W. (2014). Making flow happen: The effects of being recovered on work-related flow between and within days. Journal of Applied Psychology, 99(4), 713-722. https://doi.org/10.1037/a0035881

Demerouti, E. (2006). Job characteristics, flow, and performance: The moderating role of conscientiousness. Journal of Occupational Health Psychology, 11(3), 266-280. https://doi.org/10.1037/1076-8998.11.3.266

Demerouti, E., Bakker, A. B., Sonnentag, S., \& Fullagar, C. J. (2012). Work-related flow and energy at work and at home: A study on the role of daily recovery. Journal of Organizational Behavior, 33(2), 276-295. https://doi.org/10.1002/job.760

Duncan, T. E., Duncan, S. E., Strycker, L. A., Li, F., \& Alpert, A. (2006). An Introduction to Latent Variable Growth Curve Modeling. Concepts, Issues and Applications (Second). Mahwah, New Jersey: Lawrence Erlbaum Associates, Inc.

Eisenberger, R., Jones, J. R., Stinglhamber, F., Shanock, L., \& Randall, A. T. (2005). Flow experiences at work: For high need achievers alone? Journal of Organizational Behavior, 26(7), 755-775. https://doi.org/10.1002/job.337

Eklund, R. C. (1996). Preparing to compete: A season-long investigation with collegiate wrestlers. The Sport Psychologist, 10, 111-131. https://doi.org/10.1123/tsp.10.2.111

Ellis, G. D., Voelkl, J. E., \& Morris, C. (1994). Measurement and Analysis Issues with This article is protected by copyright. All rights reserved 
Explanation of Variance in Daily Experience Using the Flow Model. Journal of Leisure Research, 26(4), 337-356. Retrieved from http://psycnet.apa.org/psycinfo/1995-23850001

Engeser, S., \& Rheinberg, F. (2008). Flow, performance and moderators of challenge-skill balance. Motivation and Emotion, 32, 158-172. https://doi.org/10.1007/s11031-008$9102-4$

Farina, L., Rodrigues, G., \& Hutz, C. S. (2018). Flow and Engagement at Work: A Literature Review. Psico-USF, Bragrança Paulista, 23(4), 633-642.

Ford, M. T., Cerasoli, C. P., Higgins, J. A., \& Decesare, A. L. (2011). Relationships between psychological, physical, and behavioural health and work performance: A review and meta-analysis. Work \& Stress, 25(3), 185-204. https://doi.org/10.1080/02678373.2011.609035

Fullagar, C. J., \& Kelloway, E. K. (2009). Flow at work: An experience sampling approach. Journal of Occupational and Organizational Psychology, 82(3), 595-615. https://doi.org/10.1348/096317908X357903

Goodman, S. A., \& Svyantek, D. J. (1999). Person-Organization Fit and Contextual Performance: Do Shared Values Matter. Journal of Vocational Behavior, 55(2), 254 275. https://doi.org/10.1006/jvbe.1998.1682

Gottschalk, O. (1994). Verwaltungsbauten - flexible, kommunikativ, nutzerorientiert. Berlin: Springer-Verlag.

Gregory, B. T., Albritton, M. D., \& Osmonbekov, T. (2010). The Mediating Role of Psychological Empowerment on the Relationships between P-O Fit, Job Satisfaction, and In-role Performance. Journal of Business and Psychology, 25(4), 639-647. https://doi.org/10.1007/s10869-010-9156-7

Gyekye, S. A., \& Haybatollahi, M. (2015). Organizational citizenship behaviour. An empirical investigation of the impact of age and job satisfaction on Ghanaian industrial workers. International Journal of Organizational Analysis, 23(2), 285-301. https://doi.org/10.1108/IJOA-08-2012-0586

Ibrahim, M. E., Al Sejini, S., \& Al Qassimi, O. A. A. (2004). Job Satisfaction and Performance of Government Employees in UAE. Journal of Management Research, $4(1), 1-12$.

Jackson, S. A., Thomas, P. R., Marsh, H. W., \& Smethurst, C. J. (2001). Relationships between Flow, Self-Concept, Psychological Skills, and Performance. Journal of Applied Sport Psychology, 13(2), 129-153. https://doi.org/10.1080/104132001753149865

This article is protected by copyright. All rights reserved 
Judge, T. A., Thoresen, C. J., Bono, J. E., \& Patton, G. K. (2001). The Job Satisfaction-Job Performance Relationship : A Qualitative and Quantitative Review. Psychological Bulletin, 127(3), 376-407.

Kopperud, K. H., \& Straume, L. V. (2009). Flow - a positive experience. In M. Christensen (Ed.), Validation and test of central concepts in positive work and organizational psychology (pp. 30-39). Copenhagen: Nordic Council of Ministers.

Laing, A., Duffy, F., Jaunzens, D., \& Willis, S. (2004). New Environments for Working: The re-design of offices and environmental systems for new ways of working. London: Construction Research Communications Ltd.

Lan, L., Wargocki, P., \& Lian, Z. (2011). Quantitative measurement of productivity loss due to thermal discomfort. Energy \& Buildings, 43(5), 1057-1062. https://doi.org/10.1016/j.enbuild.2010.09.001

Landhäuber, A., \& Keller, J. (2012). Advances in flow research. In S. Engeser (Ed.), Advances in Flow Research (pp. 65-85). New York, NY: Springer. https://doi.org/10.1007/978-1-4614-2359-1

Little, T. D. (2013). Longitudinal Structural Equation Modeling. New York, NY: The Guilford Press.

Mäkikangas, A., Bakker, A. B., Aunola, K., \& Demerouti, E. (2010). Job resources and flow at work: Modelling the relationship via latent growth curve and mixture model methodology. Journal of Occupational and Organizational Psychology, 83(3), 795-814. https://doi.org/10.1348/096317909X476333

Motowidlo, S. J., Borman, W. C., \& Schmit, M. J. (1997). A Theory of Individual Differences in Task and Contextual Performance. Human Performance, 10(2), 71-83. https://doi.org/10.1207/s15327043hup1002

Muthén, L. K., \& Muthén, B. O. (2015). Mplus User's Guide (Seventh). Los Angeles: Muthén \& Muthén.

Nesselroade, J. R. (1991). Interindividual differences in intraindividual change. In L. M. Collins \& J. L. Horn (Eds.), Best methods for the analysis of change: Recent advances, unanswered questions, future directions (pp. 92-105). American Psychological Association.

Neufert, E. (1995). Arte de proyectar en arquitectura. España: Ediciones G. Gill SA de CV.

Nielsen, K., \& Cleal, B. (2010). Predicting Flow at Work: Investigating the Activities and Job Characteristics That Predict Flow States at Work. Journal of Occupational Health Psychology, 5(2), 180-190. https://doi.org/10.1037/a0018893

This article is protected by copyright. All rights reserved 
O’Reilly III, C. A., Chatman, J., \& Caldwell, D. F. (1991). People and Organizational Culture: A Profile Comparison Approach to Assessing Person- Organization Fit. Academy of Management, 34(3), 487-516.

Ployhart, R. E., \& Vandenberg, R. J. (2010). Longitudinal Research: The Theory, Design, and Analysis of Change. Journal of Management, 36(1), 94-120. https://doi.org/10.1177/0149206309352110

Preacher, K. J., \& Selig, J. P. (2012). Advantages of Monte Carlo Confidence Intervals for Indirect Effects. Communication Methods and Measures, 6(2), 77-98. https://doi.org/10.1080/19312458.2012.679848

Roe, R. A. (2014). Performance, Motivation and Time. In A. Shipp \& Y. Fried (Eds.), How time impacts individuals (pp. 63-110). New York, NY: US: Psychology Press.

Ryu, E. (2011). Effects of skewness and kurtosis on normal-theory based maximum likelihood test statistic in multilevel structural equation modeling. Behavior Research Methods, 43(4), 1066-1074. https://doi.org/10.3758/s13428-011-0115-7

Salanova, M., Bakker, A. B., \& Llorens, S. (2006). Flow at work: Evidence for an upward spiral of personal and organizational resources. Journal of Happiness Studies, 7(1), 122. https://doi.org/10.1007/s10902-005-8854-8

Scott, W. E. (1966). Activation Theory and Task Design. Organizational Behavior and Human Performance, 1, 3-30.

Seligman, M. E. P., \& Csikszentmihalyi, M. (2000). Positive psychology: An introduction. American Psychologist, 55(1), 5-14. https://doi.org/10.1037/0003-066X.55.1.5

Skakon, J., Nielsen, K., Borg, V., \& Guzman, J. (2010). Are leaders' well-being, behaviours and style associated with the affective well-being of their employees? A systematic review of three decades of research. Work and Stress, 24(2), 107-139. https://doi.org/10.1080/02678373.2010.495262

SPSS Inc. (2001). The SPSS TwoStep Cluster Component: A scalable component enabling more efficient customer segmentation. Technical report, Chicago: SPSS. Retrieved from http://www.spss.ch/upload/1122644952_The SPSS TwoStep Cluster Component.pdf

Turner, N., Barling, J., \& Zacharatos, A. (2002). Positive psychology at work. In C. R. Snyder \& S. J. Lopez (Eds.), Handbook of positive psychology (pp. 715-728). New York: Oxford University Press.

White, M. P., \& Dolan, P. (2009). Accounting for the richness of daily activities. Psychological Science, 20(8), 1000-1008. https://doi.org/10.1111/j.14679280.2009.02392.x

This article is protected by copyright. All rights reserved 
Williams, R. D. (1991). Performance of dynamic load balancing algorithms for unstructured mesh calculations. Concurrency: Practice and Experience, 3(5), 457-481. https://doi.org/10.1002/cpe.4330030502

Xanthopoulou, D., Bakker, A. B., Demerouti, E., \& Schaufeli, W. B. (2009a). Reciprocal relationships between job resources, personal resources, and work engagement. Journal of Vocational Behavior, 74(3), 235-244. https://doi.org/10.1016/j.jvb.2008.11.003

Xanthopoulou, D., Bakker, A. B., Demerouti, E., \& Schaufeli, W. B. (2009b). Work engagement and financial returns: A diary study on the role of job and personal resources. Journal of Occupational and Organizational Psychology, 82, 183-200. https://doi.org/10.1348/096317908X285633

This article is protected by copyright. All rights reserved 
Table 1

Type of office-work pattern fit.

\section{Type of office}

Work pattern

Cellular office (1-2 people)

Middle interactive, high complexity

Cellular office-small group (up to 4-6 people) Interactive, high complexity Group office (6-20 people)

Open offices ( $>20$ people) Interactive, low complexity Non-interactive, low complexity

This article is protected by copyright. All rights reserved 
Table 2

Fit-misfit: sample characteristics

\begin{tabular}{lcccc}
\hline & FIT & MISFIT & & \\
& $(\mathrm{n}=31)$ & $(n=52)$ & & \\
& $n(\%)$ & $n(\%)$ & $C h i^{2}$ & .43 \\
\hline Age $^{l}$ & $38.68(9.31)$ & $40.27(8.60)$ & -0.791 & \\
Sex ${ }^{2}$ & & & & \\
Female & $22(26.5 \%)$ & $35(42.2 \%)$ & 0.121 & \\
Male & $9(10.8 \%)$ & $17(20.5 \%)$ & & \\
& & & & \\
Job level & & & \\
Manager & & & \\
Highly-qualified professional & $2(2.4 \%)$ & $2(2.4 \%)$ & & \\
Technician & $10(12.0 \%)$ & $17(20.5 \%)$ & & \\
Administrative & $8(9.6 \%)$ & $13(15.7 \%)$ & 0.739 \\
Junior employees & $9(10.8 \%)$ & $18(21.7 \%)$ & \\
Other & $0(0.0 \%)$ & $0(0.0 \%)$ & \\
& $2(2.4 \%)$ & $2(2.4 \%)$ & \\
\end{tabular}

Marital status $^{2}$

Single

Married/living with partner

$8(9.6 \%) \quad 14(16.9 \%)$

Widowed

$23(27.7 \%) \quad 37(44.6 \%) \quad 0.630$

.73

Separated/divorced

$0(0.0 \%) \quad 0(0.0 \%)$

$0(0.0 \%) \quad 1(1.2 \%)$

Salary $^{2}$

Less than $600 €$

$600 €-1000 €$

$1000 €-1499 €$
$2(2.4 \%) \quad 4(4.8 \%)$

$\begin{array}{llll}4(4.8 \%) & 0(0.0 \%) & 10.434 & .06\end{array}$

$13(15.7 \%) \quad 21(25.3 \%)$ 


$\begin{array}{lcc}1500 €-1999 € & 8(9.6 \%) & 15(18.1 \%) \\ 2000 €-3000 € & 3(3.6 \%) & 12(14.5 \%) \\ \text { More than 3000€ } & 1(1.2 \%) & 0(0.0 \%) \\ \text { Organization }^{l} & & \\ \text { Organization 1 } & 5(6.02 \%) & 11(13.25 \%) \\ \text { Organization 2 } & 4(4.82 \%) & 13(15.66 \%) \\ \text { Organization 3 } & 10(12.00 \%) & 11(13.25 \%) \\ \text { Organization 4 } & 11(13.25 \%) & 12(14.46 \%) \\ \text { Organization 5 } & 1(1.20 \%) & 5(6.02 \%)\end{array}$

Note. ${ }^{1}$ Means, standard deviations, and t test. ${ }^{2}$ The number in parentheses represents the percentage of the total. 
Table 3

Descriptive statistics for the levels of the variables of interest in the current study

\begin{tabular}{lcccccc}
\hline & \multicolumn{7}{c}{ FIT } & \multicolumn{2}{c}{ MISFIT } & \\
& $M$ & SD & $M$ & SD & t & $p$ \\
\hline Flow t1 & 5.63 & 0.88 & 5.48 & 1.00 & 0.67 & .51 \\
Flow t2 & 5.76 & 0.81 & 5.29 & 1.15 & 1.94 & .06 \\
Flow t3 & 5.60 & 1.10 & 5.38 & 1.13 & 0.80 & .43 \\
Flow t4 & 5.40 & 1.19 & 5.29 & 1.30 & 0.37 & .72 \\
Flow - mean & 5.52 & 0.91 & 5.46 & 0.80 & 0.28 & .78 \\
In-role Performance t1 & 5.90 & 0.76 & 5.81 & 0.83 & 0.45 & .66 \\
In-role Performance t2 & 5.94 & 0.81 & 5.91 & 1.09 & 0.13 & .90 \\
In-role Performance t3 & 5.80 & 0.94 & 5.82 & 1.14 & -0.07 & .95 \\
In-role Performance t4 & 5.99 & 0.81 & 5.95 & 1.03 & 0.17 & .86 \\
In-role Performance - mean & 5.91 & 0.70 & 5.99 & 0.77 & -0.37 & .71 \\
Extra-role Performance t1 & 4.18 & 1.52 & 4.16 & 1.48 & 0.06 & .95 \\
Extra-role Performance t2 & 4.39 & 1.31 & 4.26 & 1.67 & 0.37 & .72 \\
Extra-role Performance t3 & 4.47 & 1.45 & 4.24 & 1.57 & 0.59 & .56 \\
Extra-role Performance t4 & 3.84 & 1.58 & 4.08 & 1.47 & -0.65 & .52 \\
Extra-role Performance - mean & 4.29 & 1.37 & 4.37 & 1.38 & -0.22 & .83 \\
\hline & & & & & & \\
\hline
\end{tabular}

This article is protected by copyright. All rights reserved 
Table 4

Bivariate correlations between the variables of interest in the current study

$\begin{array}{llllllllllll}1 & 2 & 3 & 4 & 5 & 6 & 7 & 8 & 9 & 10 & 11 & 12\end{array}$

1. Flow t1

2. Flow t2 $.51^{*}-$

3. Flow t3 .60* .63* -

4. Flow t4 $.39 * \quad .47 * \quad .65^{*} \quad-$

5. In-role $\mathrm{t} 1 \quad .75^{*} \quad .39 * \quad .45^{*} \quad .39 * \quad-$

6. In-role $\mathrm{t} 2 \quad .44 * \quad .59 * \quad .49 * \quad .34 * \quad .56 * \quad-$

7. In-role t $3 \quad .57 * \quad .65 * \quad .68 * \quad .57 * \quad .60 * \quad .74 * \quad-$

8. In-role t4 $\quad .54 * \quad .50 * \quad .51 * \quad .57 * \quad .70 * \quad .72 * \quad .77 * \quad-$

9. Extra-role t1 $\quad .39 * \quad .27 * \quad .18 \quad \begin{array}{lllllll} & .03 & .38^{*} & .36 * & .36 * & .18 & -\end{array}$

10. Extra-role t2 $\quad .19 \quad .24 * \quad \begin{array}{llllllll} & .17 & .04 & .18 & .38 * & .30 * & .07 & .71 *\end{array}$

11. Extra-role t3 $\begin{array}{lllllllllll}.29 * & .32 * & .22 & .13 & .30^{*} & .28^{*} & .31 * & .26 * & .68^{*} & .77^{*} & -\end{array}$

12. Extra-role t4 $\quad .27 \quad .20 \quad .27 * \quad .26 * \quad .32 * \quad .33 * \quad .43 * \quad .36 * \quad .67 * \quad .67 * \quad .80 * \quad$ -

$* p \leq .05$ 
Table 5

Parameter estimates (unstandardized forms) of latent growth models for flow and in-role and extra-role performance (each in a separate analysis)

\begin{tabular}{|c|c|c|c|c|c|c|c|c|}
\hline \multirow[b]{2}{*}{ LGM } & \multicolumn{2}{|c|}{ Growth parameters } & \multicolumn{6}{|c|}{ Goodness-of-fit indexes } \\
\hline & Estimate & $p$ value & $X^{2}$ & df & $p$ value & CFI & TLI & RMSEA \\
\hline Flow & & & 2.826 & 5 & .73 & 1.00 & 1.03 & 0.00 \\
\hline \multicolumn{9}{|l|}{ Means } \\
\hline Level & 5.52 & .01 & & & & & & \\
\hline Linear trend & -0.05 & .30 & & & & & & \\
\hline \multicolumn{9}{|l|}{ Variances } \\
\hline Level & 0.67 & .01 & & & & & & \\
\hline Linear trend & 0.06 & .06 & & & & & & \\
\hline In-role & & & 2.248 & 4 & .69 & 1.00 & 1.02 & 0.00 \\
\hline \multicolumn{9}{|l|}{ Means } \\
\hline Level & 5.82 & .01 & & & & & & \\
\hline Linear trend & 0.04 & .17 & & & & & & \\
\hline \multicolumn{9}{|l|}{ Variances } \\
\hline Level & 0.53 & .01 & & & & & & \\
\hline Linear trend & 0.02 & .31 & & & & & & \\
\hline Extra-role & & & 5.45 & 4 & .24 & 0.99 & 0.99 & 0.07 \\
\hline \multicolumn{9}{|l|}{ Means } \\
\hline Level & 4.18 & .01 & & & & & & \\
\hline Linear trend & -0.05 & .28 & & & & & & \\
\hline \multicolumn{9}{|l|}{ Variances } \\
\hline Level & 1.69 & .01 & & & & & & \\
\hline Linear trend & 0.11 & .01 & & & & & & \\
\hline
\end{tabular}


Table 6

Confirmation of the hypotheses stated

Hypotheses stated

Supported or not

Hypothesis la: The initial level of flow is positively related to the initial level of

Supported

in-role performance.

Hypothesis $1 b$ : The initial level of flow is positively related to the initial level of

Supported extra-role performance.

Hypothesis $2 a$ : The change in flow is positively related to the change in in-role

Supported performance.

Hypothesis $2 b$ : The change in flow is positively related to the change in extra-

Supported role performance.

Hypothesis $3 a$ : Office type-work pattern fit is positively associated with the in-

Not-supported role performance level.

Hypothesis $3 b$ : Office type-work pattern fit is positively associated with the

Not-supported extra-role performance level.

Hypothesis 4: Office type-work pattern fit is positively associated with the level Supported of flow.

Hypothesis $5 a$ : Office type-work pattern fit is positively associated with the inSupported role performance level through the flow level.

Hypothesis $5 b$ : Office type-work pattern fit is positively associated with the Not-supported extra-role performance level through the flow level. 


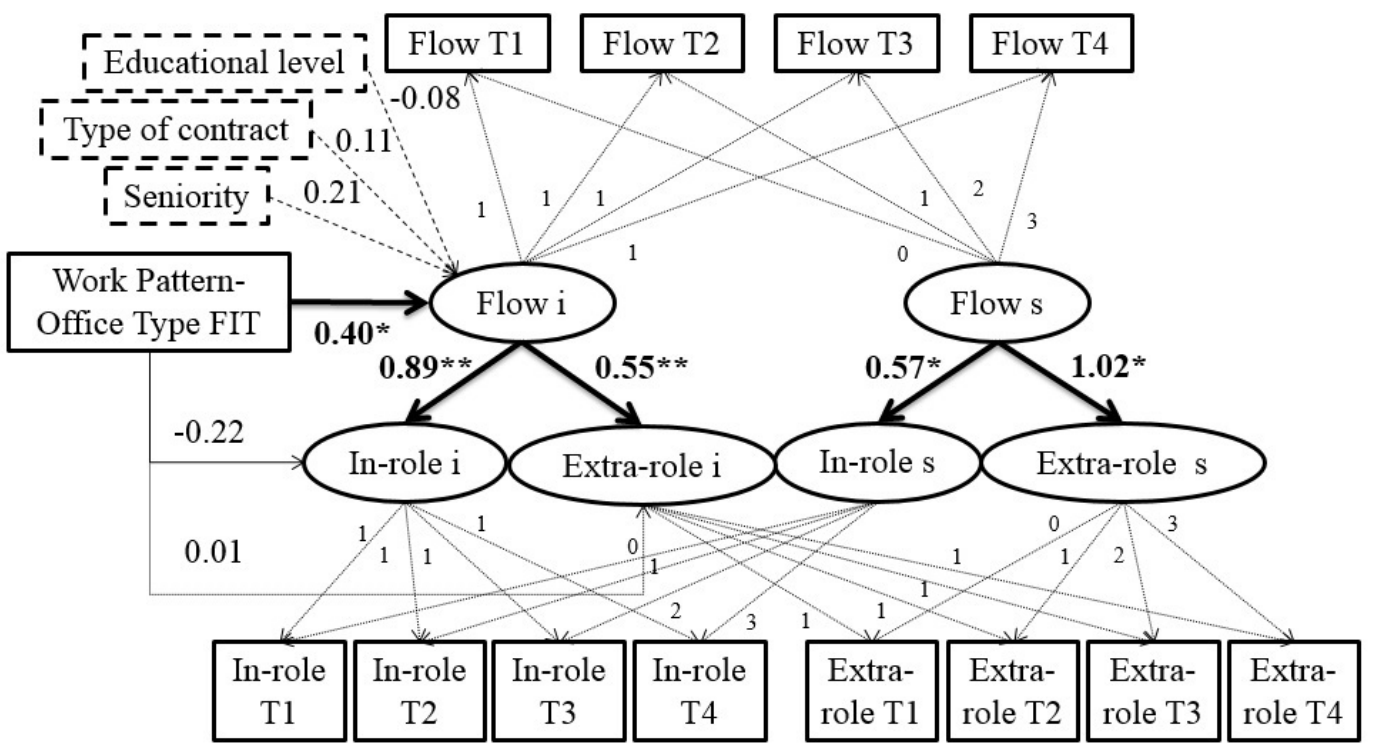

Figure 1. Latent Growth Modeling Results

Note. ** $p \leq .001 ; * p \leq .05$

Solid lines depict main variable effects; dotted lines depict control variables effect; dashed lines depict continuous observed variables in which the latent factors ( $i$ and s) were based. The $i$ is a constant for any given individual across time; thus, the factor loadings of the observed variables were set al 1 for each measurement point (see Duncan et al., 1999). The s describes individual differences in the constant rate of mean-level change across measurement points; this, the factors loadings were fixed in ascending order (0, 1, and 2) (see Duncan et al., 1999).

$$
\text { apps_12251_f1.jpg }
$$

